\title{
The effectiveness of entrepreneurship education: What matters most?
}

\author{
M. Lekoko, E. M. Rankhumise ${ }^{\star}$ and P. Ras \\ Department of Management and Entrepreneurship, Tshwane University of Technology, Staatsartillerie Road, Pretoria \\ 0183, South Africa.
}

Accepted 15 December, 2012

\begin{abstract}
A growing body of academic research has examined the effectiveness of entrepreneurship education with the aim of raising students' awareness of self-employment as a career option and creating an enterprising culture amongst them. The move towards self-employment is, and will continue to become, an increasingly important element of economic growth and development. This paper aims to explore and investigate entrepreneurship education at Botswana's two universities to determine and evaluate its effectiveness. In the process of selecting the research population, 400 students were identified within two universities. A convenient sampling approach was used to select the respondents and a selfadministered questionnaire with closed questions was used to collect data. The results indicate that entrepreneurship education is not appropriately developed in Botswana to effectively equip students with entrepreneurial skills and competencies that will help them to choose entrepreneurship as a career option. The article provides a comprehensive analysis of the state of entrepreneurship education in Botswana to create a platform for further research in the area of entrepreneurship education, particularly at higher education level. The findings provide useful information on effective teaching methods in the area of entrepreneurship.
\end{abstract}

Key words: Entrepreneurship, entrepreneurship education, teaching methods, Botswana.

\section{INTRODUCTION}

Entrepreneurship is a new and growing field in scientific research and education. This in considerable academic efforts focused on entrepreneurship education, helping this field to develop and gain momentum and to contribute to the understanding thereof (Fayolle et al., 2006; Gurol and Atsan, 2006:25).

Over time, the need for entrepreneurship to solve social issues such as unemployment through creating jobs has become obvious, especially in developing countries. To understand this phenomenon of entrepreneurship, academic research into this field has expanded around the world (Fayolle and Gailly, 2008:569). This is evident in the research that started at Harvard Business School in 1945 with their main interest in the explosive growth of entrepreneurship education (Kirby, 2004:510).

\footnotetext{
*Corresponding author. E-mail: RankhumiseEM@tut.ac.za.
}

Entrepreneurship education must equip future entrepreneurs with the necessary skills to meet the need to accelerate economic development through generating new ideas and converting those ideas into viable and profitable ventures (Tucker and Selcuk, 2009:142).

The entrepreneurship education concept has become an important economic and social phenomenon as well as a popular research subject. It has also become an academic and teaching field (Fayolle and Gailly, 2008:569), considering the rapidly increasing number of universities worldwide, which offer entrepreneurship programmes and courses.

The first class of 1945 at Harvard Business School sparked the interest in and the explosive growth of entrepreneurship education in the global village (Kirby, 2004:510). A number of good studies have traced the development and state of entrepreneurship education (Kuratko, 2003; Garavan and O'Cinneide, 1994). These studies have revealed the remarkable progress that has 
been made in this field, helping it to develop and gain momentum (Fayolle et al., 2006; Gurol and Atsan, 2006:25).

Scientific research in entrepreneurship is not limited to just one discipline and has also been an important research field among scholars alike worldwide for some considerable time (Fayolle et al., 2006; Gurol and Atsan, 2006:25), with the emphasis on entrepreneurship education (Nabi and Holden, 2008:545). The positive relationship between education and business creation has been acknowledged by international literature from different perspectives and approaches (Niyonkuru, 2005:6) and according to scholars and researchers, there is a possibility to increase entrepreneurial orientation (ability) through education.

It is also widely accepted that entrepreneurship can be learnt and a positive relationship can be found between higher education levels and high levels of entrepreneurial activity (Niyonkuru, 2005; GEM, 2006). Despite the fact that entrepreneurial skills are teachable, schools are not teaching them. Schools teach learners how to work for entrepreneurs, and not the process of acquiring the knowledge on how to establish and manage their own businesses (Alberti et al., 2005:458). Moreover, the trend in many universities in the USA, Europe, East Asia and Latin America is to develop or expand entrepreneurship programmes and design unique and challenging curricula for entrepreneurship education (Kuratko, 2003:10). The purpose of this paper is to determine the effect of entrepreneurship education programmes on enhancing students' self-confidence about their ability to start a business. The paper aims to explore and investigate entrepreneurship education at Botswana's two universities to determine and evaluate its effectiveness.

\section{Entrepreneurship education in universities}

Entrepreneurship education is critical for developing entrepreneurial skills, attitudes and behaviours that form the basis for the economic growth of a country. Entrepreneurship education at universities can have a positive influence in attitudes towards entrepreneurship, and in turn promote entrepreneurship as a useful and respectable career prospect for graduates (Galloway and Brown, 2002:399). According to Matlay (2006:709), many universities claim that they offer entrepreneurship education at an advanced level whilst focusing on writing business plans, acquiring start-up capital and developing managerial skills, particularly nascent entrepreneurs.

A study of 15 leading US entrepreneurship education programmes found that the primary goal for the majority of the programmes was to increase the awareness and understanding of entrepreneurship as a process (Hamidi et al., 2008:306). The second major goal was to increase students' awareness of entrepreneurship as a career possibility. Universities, especially technical universities, can be seen as engines of scientific and technological invention and play an important role in transforming the invention and technological development into innovation (Volkmann et al., 2009:44).

Universities play a key role in harnessing the talents of students, graduates and researchers. A university can be conceptualised as a societal innovation system, and entrepreneurship education, when embedded in such a system, could be regarded not only as a task of producing entrepreneurially oriented competent individuals, but also reproducing the social mechanisms that underpin and facilitate the birth and growth of businesses (Petridou et al., 2009:29). In addition, universities play a key role as entrepreneurial hubs, connecting researchers, students, entrepreneurs, business enterprises and other stakeholders. Nevertheless, access and exposure to entrepreneurship within educational systems at all levels is important as they are intended to target audiences even outside universities by way of outreach programmes (Volkmann et al., 2009:9).

In order to get a clear understanding of the term 'entrepreneurship education' as used in this research, it is vital to provide a pertinent and permissible definition of entrepreneurship and entrepreneurship education.

\section{Entrepreneurship}

Entrepreneurship will be defined as the process by which a prospective entrepreneur or entrepreneur pursues opportunities without regard to the resources that they presently control. This essentially means the ability of the entrepreneur to combine all other productions means namely, natural resources, capital and labour to ensure that the business become a success (Strydom and Nieuwenhuizen, 2007:2). Rwigema and Venter (2004) further define entrepreneurship as a "process of conceptualizing, orgnanising, launching and through innovation nurturing a business opportunity into a potential growth venture in a complex and unstable environment"

\section{Entrepreneurship education}

For the purpose of this research an understanding of the concept of entrepreneurship education is needed. Shepherd and Douglas (1997) as cited by Solomon (2007) adopted the following definition: "the essence of entrepreneurship education is the ability to envision and chart a course for a new business venture by combining information from the functional disciplines and from the external environment in the context of the extraordinary uncertainty and ambiguity which faces a new business venture". Furthermore, Alberti et al. (2004) define entrepreneurship as "the structured formal conveyance of 
entrepreneurial competencies, which in turn refers to the concepts, skills and mental awareness used by individuals during the process of starting and developing their growth-oriented ventures. Entrepreneurship manifests itself in creative strategies, innovative tactics, uncanny perception of trends and market move changes, courageous leadership when the way forward is not obvious and so on.

Various studies on entrepreneurship education have been conducted in Botswana (Swartland, 2008; World Bank, 2004), and for the purpose of this article we will focus on two of these. The first was a study of entrepreneurship education in Botswana and the significance of institutional preparation conducted by Swartland in 2008. The focus was on post-primary education and technical and vocational education and training (TVET). The second study, commissioned by the World Bank, identified and investigated the integrated entrepreneurship education (IEE) approach in Botswana, Kenya and Uganda. IEE covers the teaching of knowledge and skills that will enable the individual student to plan, start and run his/her business and it is delivered as an integrated part of the curriculum at an acknowledged education and training institution within the national educational system. The latter study was limited to entrepreneurship education (EE) provided to regular, full-time students in general secondary education (GSE) and TVET at secondary and post-secondary levels. The study was a review where available documents were the prime source of information.

Both studies focused on post-secondary and TVET institutions. It appears, though, that little research on entrepreneurship education has been conducted in universities in Botswana and the body of specialist knowledge on entrepreneurship education regards universities as the key role player in shaping attitudes, supplying knowledge and generally enabling students as enterprising customers and considering them as entrepreneurial products (Anderson and Jack, 2008:259). In this paper, the focus of this study was limited to two universities in Botswana to benchmark with the recommended international body of specialist knowledge. Thus to capture, use and develop the innate abilities of the students, those who should represent the future as the most intelligent stratum of our society, is a major academic challenge (Anderson and Jack, 2008). Currently, universities are expected to play a new role in society, in addition to research and teaching, by applying a 'third mission' namely that of economic development. This development has been apparent in many US universities for decades, and is currently accelerating also in Europe (Rasmussen and Sorheim, 2006:185).

The primary purpose of entrepreneurship education in higher education institutions should be to develop entrepreneurial capacities and mindsets (European Commission, 2008:23). A perceived lack of relevant experience and self-confidence are two often-cited reasons for new graduates not engaging in entrepreneurship after graduation. It is perceived that the university experience could bridge this cap. The learning experience needs to build depth and breadth in awareness and understanding of entrepreneurship education. Although not applicable in all cases, the general approach would be to provide exposure and positive and motivational experiences during the early stages of university life. This then provides a platform from which to build depth and capability in preparation for an entrepreneurial career at the point of exit. The important point here is one of progression, not only through universities, but also through the whole education system at all levels (European Commission, 2008:23).

Higher education institutions can help create a more entrepreneurial disposition among young people by instilling a clear understanding of risks and rewards, teaching opportunity seeking and recognition skills as well as creating and building enterprises. They can also play a role in developing entrepreneurial traits in students (Jesselyn and Mitchell, 2006:349). With the recent increase of university graduates and self-employment and business ownership being perceived as growing employment opportunities, it has been recognised and acknowledged that higher education needs to be equipping its graduates better for the diverse range of skills required to manage this type of work (Carey and Naudin, 2006:522).

\section{Relevance of entrepreneurship education}

According to Cheng et al. (2009) there has been a growing burgeoning of entrepreneurship education since mid - 1990s as an emergence of new economic direction whereby knowledge has become an predominant resource for economic activities. This was matched by a corresponding growth in the number of courses offered by both academic institutions and by enterprise agencies of one sort or another (Jack and Anderson 1999). They further argue that this development is a consequence of a variety of interrelated changes in the national and international economy. They identify three sources of demand: governmental, students, and education and the business world (Niyonkuru, 2005). The governmental source of demand is primarily economic and is driven by the shift towards a post-Fordist economy, aimed at developing an entrepreneurial culture oriented to job creation (Jack and Anderson, 1999; Niyonkuru, 2005). It is documented that most new jobs arise from entrepreneurial small firms (Nieman and Nieuwenhuizen, 2008). Unemployment is a rampant challenge in many communities and as such most people seeking employment depend on entrepreneurs to embark on new ventures and hire them.

The second source of demand for entrepreneurship 
education is the students. Jack and Anderson (1999) suggest that there are two sets of reasons why students may want to study entrepreneurship. Firstly, the student may plan to start their own business; secondly, they may wish to acquire knowledge, which will be helpful in their careers in larger organisations. Some researchers even propose that some students may be attracted to enterprise learning as insurance against economic downturn. The third source of demand for entrepreneurial education is business itself. Alberti et al. (2004) point out that, on one hand, there seems to be a general shortage of managerial skills in small and micro enterprises and on the other hand, within larger companies there is a need for managers who are oriented to the development of new business initiatives to ensure a continuous renewal of products and services.

\section{ISSUES IN ENTREPRENEURSHIP EDUCATION CURRICULUM}

Despite the fact that the debate surrounding whether or not entrepreneurship can be taught continues, there has been considerable interest in entrepreneurship education over the last couple of decades (Henry et al., 2005). Conceptual and contextual convergence is of paramount importance to the ongoing debate of whether entrepreneurs are born or made and to issues surrounding entrepreneurship education and its impact upon entrepreneurial activities (Matlay, 2006). Curriculum for entrepreneurship education is being developed, refined and debated (Niyonkuru, 2005). The rationale for developing and refining the curriculum is based on empirical evidence that it has concentrated on preparing students for the "take-a-job" option instead of "make-ajob" option and there is therefore an urgent need for young people to be trained and educated in the field of entrepreneurship. This will hopefully encourage them to become job creators instead of job seekers once they leave the educational system (Jesselyn and Mitchell, 2006).

Notwithstanding inherent research flaws and generalisation problems, the continuous expansion in entrepreneurship education has contributed to the emergence of a relevant curriculum, together with a range of related delivery platforms and assessment methods (Matlay and Carey, 2007). These authors, further state that there are considerable variations in course design, content and assessment, however, have ignited acrimonious debates amongst various stakeholders, mainly in relation to course appropriateness and cost-effectiveness.

The challenge to educators will be to craft courses, programmes and major fields of study that meet the rigors of academia while keeping a reality-based focus and entrepreneurial climate in the learning experience environment (Solomon, 2007). The author further asserts that entrepreneurship is an ongoing process that requires myriad of talents, skills and knowledge, leading to unique pedagogies capable of stimulating and imparting knowledge simultaneously. However, Fayolle and Gailly (2008) are of the view that there is nothing further removed from the truth and numerous ontological, theoretical, pedagogical and practical challenges remain impediment for entrepreneurship to make some strides. Among others, two recent articles (Katz, 2003) published in leading journals in the field propose, each in their own way, a comprehensive literature review of the subject aimed at defining the characteristics of this development as well as its main limitations and key challenges. At the ontological and theoretical levels, there is no consensus regarding what entrepreneurship is.

\section{Key issues and challenges in entrepreneurship education}

According to Garavan and O'Cinneide (1994), the major challenge for researchers and educators in relation to entrepreneurship education is the appropriateness of curricula and training programmes. Jack and Anderson (1999) add that there is a need to teach students theory to support their practical learning experience. Researchers and educators need to provide a conceptual background, that allow students to understand and engage with the real business world. Fiet (1998) as cited in Jack and Anderson (1999) proposes that if the substance of what is taught to students studying entrepreneurship is to improve, the following needs to happen: (i) pursue theory-driven research agendas and be actively seen to do so; and (ii) expose students to the notions of why some entrepreneurs succeed and others fail.

More of research should be theory-driven rather than descriptive and it should integrate research findings and theory in a way that can be understood and applied by students. From a researcher's perspective, Alberti et al. (2004) identify five main issues in debating how to develop entrepreneurship through education, namely the variety of audience, objectives, the content of entrepreneurship courses, pedagogies and assessment methods. However, they mention that the debate around audiences and objectives seems to be closed due to the apparent consensus among scholars, whereas the debate around pedagogies and content is still open.

All five issues in entrepreneurship education are related to one another. According to Niyonkuru (2005), educational goals depend on the learning audience. Assessment can be done only if goals are fixed, and pedagogies can be chosen depending on content and audiences; assessment depends on both content and pedagogies. According to this view, assessment appears to be the most relevant dimension in entrepreneurship education, since it is the issue with the highest number of 
incoming relationships. This means that it is the issue that is most influenced by all the others (Alberti et al., 2005) and hence requires more research.

According to Alberti et al. (2004), for effective entrepreneurship education there should be a relationship between the goals of the entrepreneurship programme, the audiences to which the programme is delivered, the content of the entrepreneurship courses or modules, the method of delivery or pedagogy and finally the assessment that will be used. Niyonkuru (2005) concludes that the five core research issues in entrepreneurship education and their relationship have important implications for the development of an effective learning process.

Given the nature and framework of this paper, it is worth noting that this study will focus on goals/objectives, the content of entrepreneurship courses, teaching and assessment methods, that is, four of the five-core research issues.

\section{Objectives of entrepreneurship education}

Entrepreneurship education is aimed at equipping learners to be able to establish their own businesses as soon they complete their studies. Its objectives are to; (i) provide opportunity for students to learn about entrepreneurial orientation. (ii) increase students' awareness of entrepreneurship as a career option and (iii) increase self-efficacy among the students.

\section{Content of entrepreneurship}

In order for entrepreneurship to be effective, its content should cover aspects such as idea generation, business planning to the identification of the products or services, how to conduct market research and how to write business plan. Over and above all these aspects, it is also imperative to include in the content skills as identified by Hisrich and Peters $(1988 ; 20)$ required by entrepreneurs to be successful and these ranges from (i) technical skills which relates to oral communication, technical management as well organizing skills. (ii) personal entrepreneurial skills -this includes attributes such as risk taking and innovation. (iii) business management skills- relates to generic management functions, decision-making, marketing and financial accounting skills. Once students are exposed to these interventions, there would be a greater possibility of enhancing self-efficacy among them.

\section{Teaching approaches and methods of entrepreneurship education}

It is apparent from the literature that the learning methods employed in entrepreneurship education and training programmes vary considerably, from lectures, presentations and handouts to video and case studybased learning, with group discussion and role plays (Henry et al., 2006). The study of what should be taught (learning content) and how it should be taught (pedagogies) has dominated interest in many researchers. Jack and Anderson (1999:117) posit that education can serve a preparatory function in relation to new venture creation, the transfer of knowledge and the acquisition and development of relevant skills would be expected to increase the self-confidence of the students to start their own businesses.

Very little is known about effective teaching techniques for entrepreneurship education (Alberti et al., 2005) and research and knowledge about how to teach entrepreneurship remains relatively underdeveloped despite the growing demand for more entrepreneurialoriented graduates (Kirby, 2002). Teaching approaches and methods may involve learning by doing, immersion in real-life situations, case studies and talks by entrepreneurs, or more didactical and conventional procedures whose efficiency could be assessed (Fayolle et al., 2006). For example, what impacts on attitudes, perceptions and intention would have the development by students of entrepreneurship education on their own ideas and/or projects? What about working on a case study or attending a traditional classroom lecture?

In an attempt to assess alternative approaches to teaching entrepreneurship, Henry et al. (2006) compared the case method of teaching with the project method, by conducting a survey amongst MBA students and alumni at the University of Calgary. They discovered that the students felt the case method was effective in developing analytical skills and the ability to synthesise information. However, courses based on the project method were perceived to develop and enhance knowledge and understanding of the subject area, as well as the ability to evaluate, and were felt to be more effective in teaching entrepreneurship. According to Kolb (1984:30) knowledge and skills are usually achieved through experiential learning. In order for learners to be effective in their learning, they need to acquire abilities such as concrete experience abilities, reflective abilities, abstract conceptualisation abilities and active experimentation abilities.

\section{Assessment of entrepreneurship education}

Research on pedagogy in entrepreneurship education appears to focus mainly on programme design and implementation than on the efficacy of assessment practice (Pittaway et al., 2009:72). When exploring the research bibliography of the National Council for Graduate Entrepreneurship (NCGE), a similar conclusion can be drawn. Pittaway et al. (2009) further posted that 
despite a database of over 700 citations, including recent working papers, there are only three papers listed that have a specific interest in assessment practice. While the limitations of systematic literature review and the NCGE's bibliographical database are taken into account, it does seem that there is a scarcity of work specifically addressing assessment practice in enterprise education published in entrepreneurship journals (Pittaway et al., 2009:72).

Assessment is a central element in the overall quality of teaching and learning in higher education. Well-designed assessment sets clear expectations, establishes a reasonable workload and provides opportunities for students to self-monitor, rehearse, practise and receive feedback. Assessment is an integral component of a coherent educational experience (Pittaway et al., 2009:72). It has been observed that impact assessment in entrepreneurship education is currently receiving increasing attention from various stakeholders (Mwasalwiba, 2010:33).

Little attention has been dedicated to how to measure the overall effectiveness of entrepreneurship education programmes for individuals and society (Alberti et al., 2005). Niyonkuru (2005) argued that there are no standardised methods for assessing the results of entrepreneurship education programmes for individuals and society. It is highly advocated that the main problems relating to the assessment of entrepreneurship education may lie in measuring output from the entrepreneurship education process.

Alberti et al. (2005) assert that the lack of generally accepted measures is due to different factors characterising entrepreneurship education, such as target groups, university/schools vs. entrepreneurship education/training focus, objectives of entrepreneurship education, levels of analysis and time dimension.

Based on the articulated background, the study aimed to investigate how well the two universities in Botswana are preparing students taking entrepreneurship courses for entrepreneurship as a career option. To address this concern, this study tried to determine whether entrepreneurship is appropriately designed to prepare students for self-employment and promote enterprise intentionality amongst learners. The University of Botswana (UB) and Limkokwing University were selected for this research.

The above articulations can thus be hypothesised as follows: (i) entrepreneurship education programmes encourage entrepreneurship and self-efficacy in the creation of businesses upon completion. (ii) The teaching methodologies are supportive for entrepreneurial competencies. (iii) Entrepreneurship education enhances self efficacy among university students. (iv) entrepreneurship education is taught in a practical way.

\section{RESEARCH METHODOLOGY}

This research used a structured questionnaire as survey instrument to determine students' perceptions of the effectiveness of the entrepreneurship education offered to them. The questionnaire was completed by a number of students drawn from the two universities. In this regard the selection of objects was based on the convenient sampling approach. Prior to data collection, the researcher requested and obtained permission from the research committees of two universities to conduct the study. The self-administered questionnaires were personally distributed by the researcher to targeted students of the two universities and were completed within a fixed session. This method allowed respondents to clarify and pose questions. Of the 400 questionnaires distributed, 325 were returned, constituting a response rate of $81.25 \%$.

\section{RESULTS AND DISCUSSION}

\section{Sample realisation}

Of the 325 respondents from the two universities, a total of $60.25 \%$ were registered for degree level, $36.59 \%$ for diploma level and only $3.15 \%$ for certificate level (academic level). A higher number of respondents $(60.25 \%)$ were in their final year of study, which made them more relevant to the study because they would soon be entering the job market. Of the 325 respondents, $65.54 \%(\mathrm{~N}=213)$ attended the University of Botswana and $34.46 \%(\mathrm{~N}=112)$ Limkokwing University. The University of Botswana has a high student enrolment compared to that of Limkokwing University. UB is the only traditional university in Botswana.

\section{Findings}

The results shown in figure 1 are based on a multiple choice question approach, where students were asked what they thought was the primary aim of the entrepreneurship courses offered.

The four options were: (1) to prepare students on how to start businesses; (2) to teach general business skills; (3) to teach students about the role of entrepreneurship in economic development and job creation; and (4) other and the results are 41.5, 33.33, 23.86 and $4 \%$ respectively. The responses to the question are depicted in Figure 1.

From these results, there is a clear indication that the main aim of entrepreneurship courses from the respondents' perspective $(41.50 \%)$ is to prepare students to start a business, to teach students the general business skills, the role of entrepreneurship in economic development and job creation. Students are therefore only sensitizing students to starting their own businesses but not given the opportunity to practically experience entrepreneurship. This in turn will result in fewer students taking entrepreneurship as a career option after completion of their studies due to lack of experiencing entrepreneurial activities.

The second question related to teaching/learning content. Respondents were presented with a list of six 


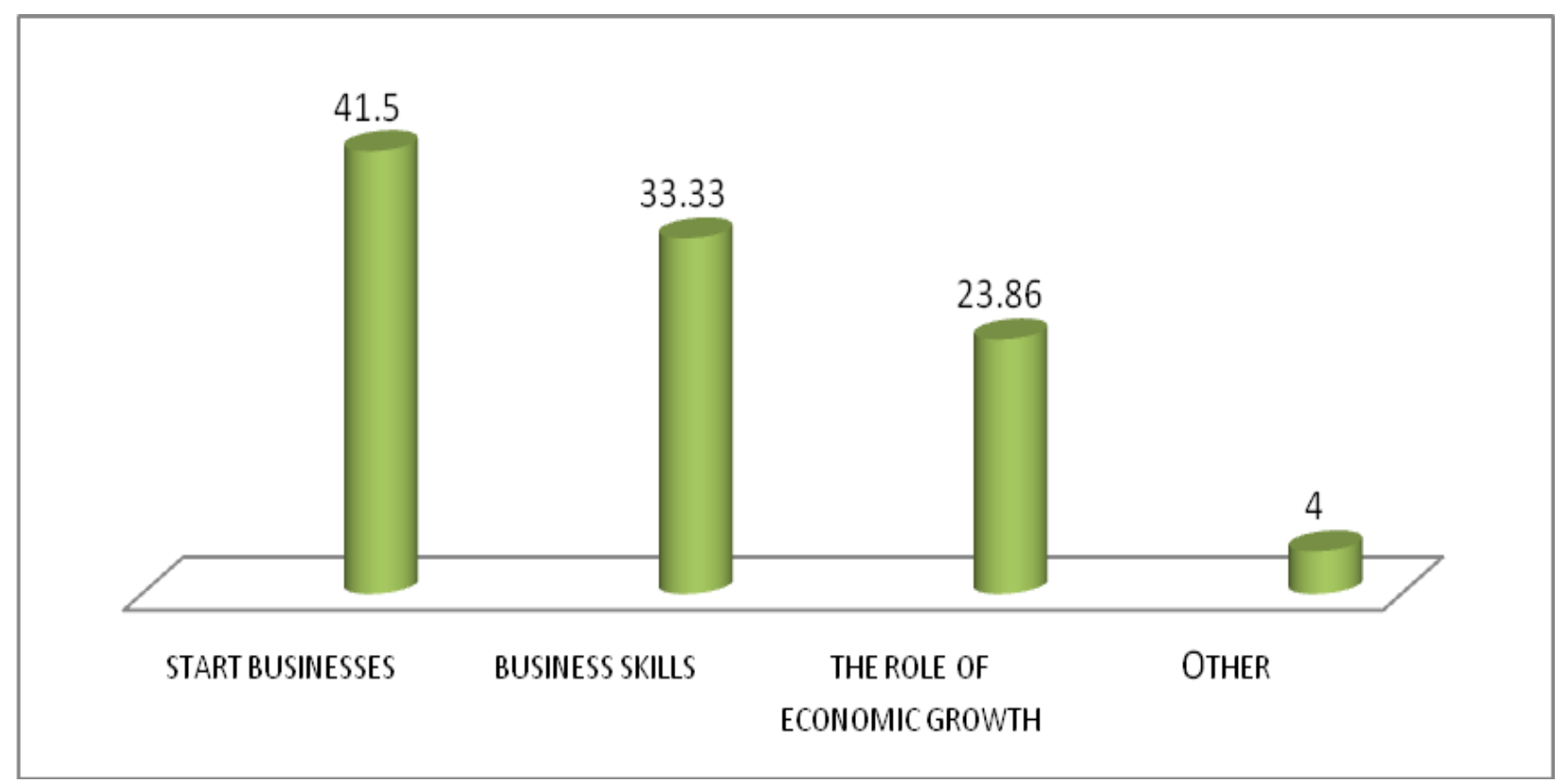

Figure 1. Aims of teaching entrepreneurship courses.

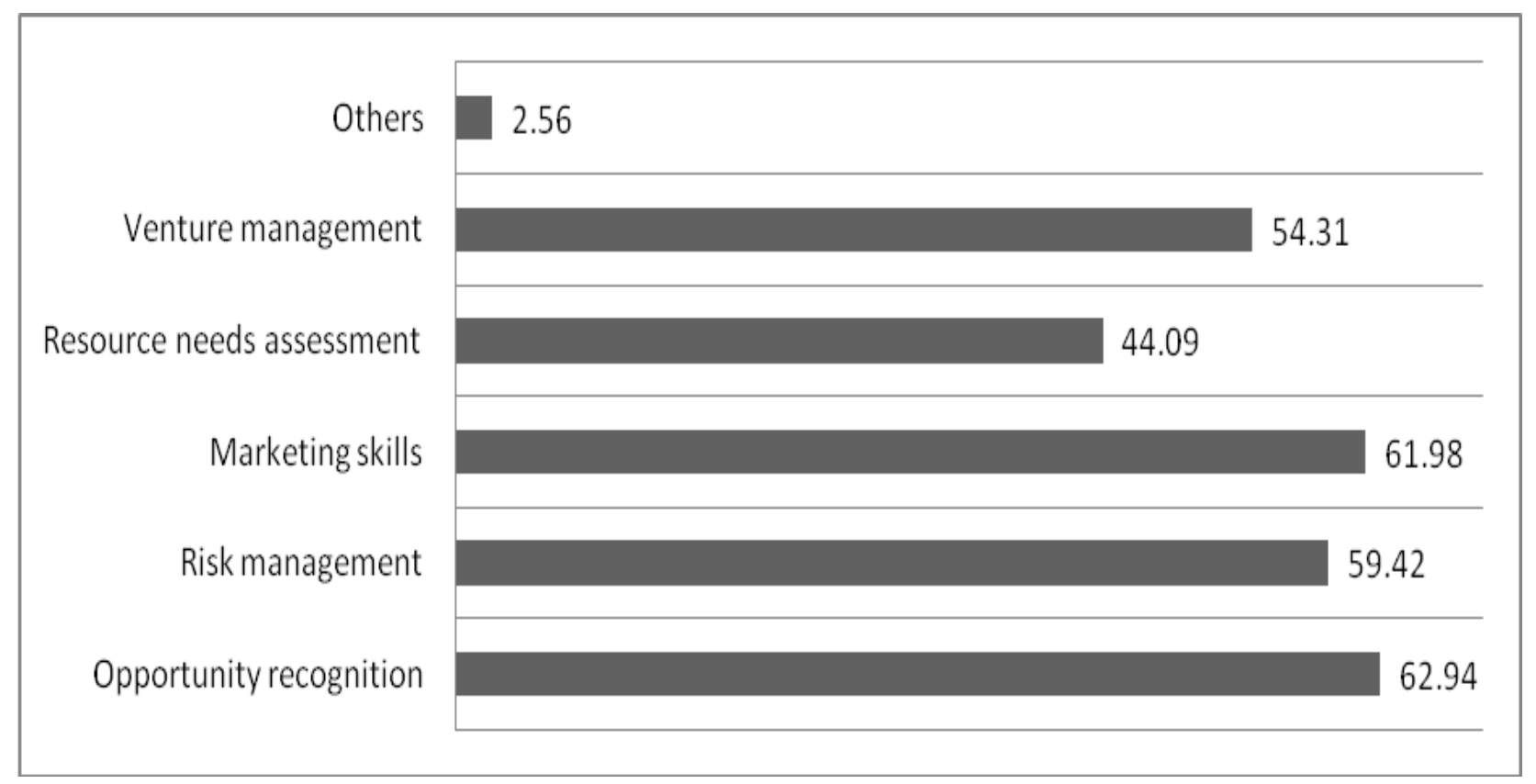

Figure 2. Learning content.

options to choose from. The results are presented in Figure 2. It is clear from the figure that $62.94 \%$ of entrepreneurship courses offered at the two universities in Botswana focused on venture management; $61.98 \%$ on marketing skills; $59.92 \%$ on risk management; $54.31 \%$ included venture management, $44.09 \%$ included resource management and $2.56 \%$ included other content.
The above results confirms what Alberti et al. (2004) found, namely that most business schools normally offer courses in entrepreneurship that foster general business knowledge (that is, knowledge that applies to business in general, both new and established firms) and venturespecific knowledge (that is, knowledge that is fairly general to ventures). The findings in the context of this 


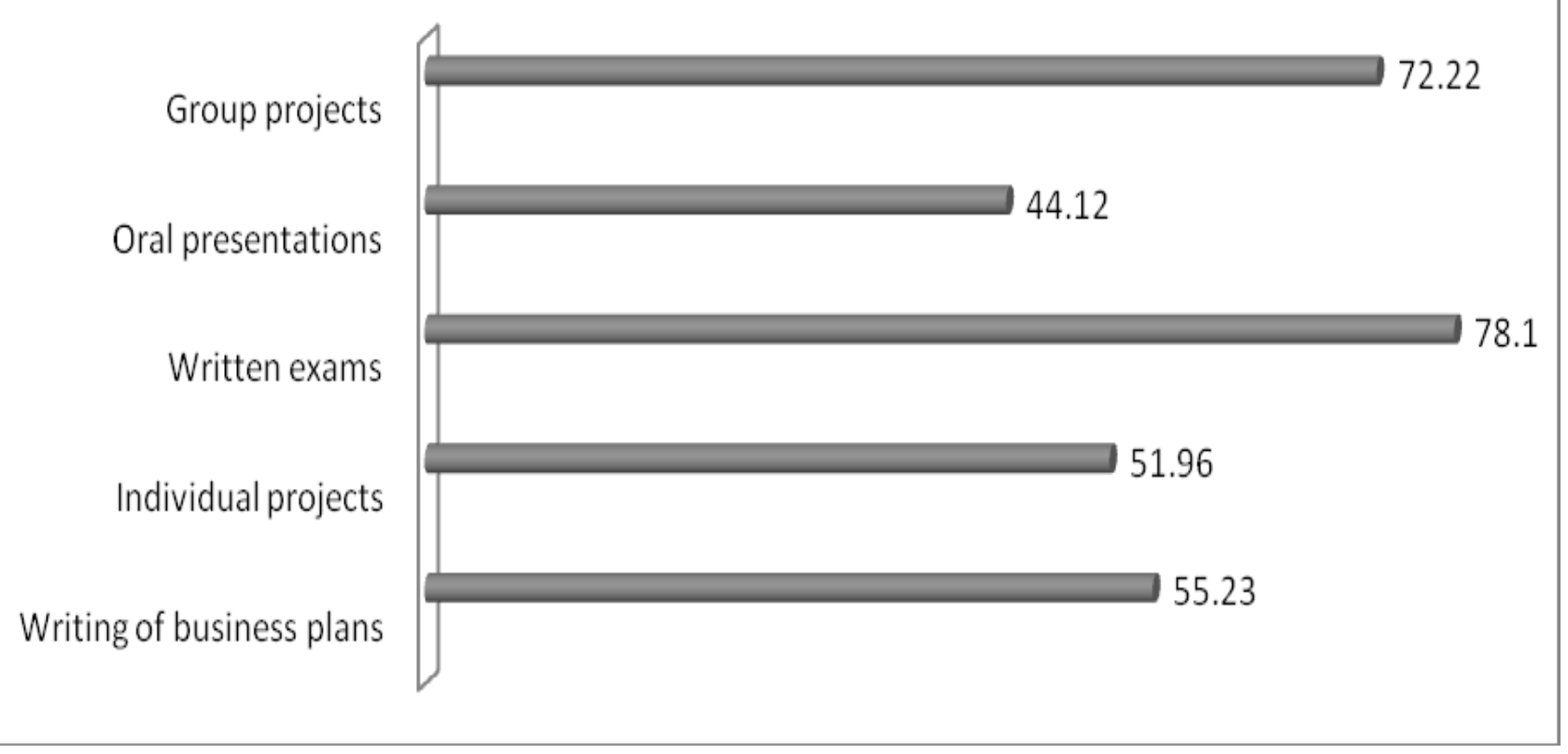

Figure 3. Assessment methods.

study reveal that $61.98 \%$ of courses included marketing topics, $59.42 \%$ risk management and $54.31 \%$ venture management topics. Respondents were asked to identify the assessment methods in entrepreneurship education that were used at their university. Figure 3 depicts the results of the assessment methods used in entrepreneurship education.

Commonly used methods used in entrepreneurship courses in the two universities in Botswana were written exams $(78.1 \%)$ and group projects $(72.22 \%)$. The third most commonly used assessment method was writing business plans (55.23\%). In the context of this study it can be argued that traditional assessment methods still prevail at the two universities as they predominantly use written exams and group projects for assessment.

A chi-squared test was conducted to test the significance difference between variables. The results indicate an insignificant association/relationship between the institutions and the perceived effect of entrepreneurship programmes on improving students' entrepreneurial attitudes and intentions, at the $5 \%$ level of significance, with a $p$-value of $>0.05$. The different environments that students operate in and the differences in the syllabus can attest this. These students were from two different institutions with a different programme focus altogether. Another test was conducted and the results show an insignificant association between the institutions and the perceived focus of entrepreneurship programmes in terms of programme content, at a $5 \%$ level of significance, with a p-value of $>0.05$. This may be for the above-mentioned reasons, such as the universities being different, different programme focus and syllabus.
It appears that entrepreneurship education at the two universities in Botswana is not appropriately developed to effectively equip students with the relevant entrepreneurial skills and competencies that will help them to choose entrepreneurship as a career option. With regard to the borrowed entrepreneurship education issues such as course aims and objectives, teaching/learning content and methods and assessment methods, it is apparent that the curriculum at the two universities in Botswana is based primarily on the theoretical transfer of knowledge rather than on experiential learning, and that the more traditional but less innovative assessment methods are the norm in Botswana. Students at the two universities in Botswana are not equipped effectively with the relevant skills and knowledge to experience real activities involved in entrepreneurship and is given little or no practical training for becoming successful entrepreneurs. Although entrepreneurship students have an advantage over other graduates when it comes to understanding entrepreneurial ventures, more efforts should be directed at creating an entrepreneurial culture, orientation and skills, and incorporating entrepreneurship in all educational, development and investment strategies and policies.

\section{CONCLUSION}

The results from this study indicate that the provision of entrepreneurship education at the two universities in Botswana does not conform to what the literature 
recommends as best practice in entrepreneurship education. The researchers established that there is little influence from the two universities in Botswana on students to develop an entrepreneurial mindset and create an enterprise culture among them. Students have little or no opportunity to practically experience entrepreneurship because the programmes focus more on the theoretical transfer of entrepreneurship knowledge than on the practical aspects. The programme should essentially make students more enterprising. Entrepreneurship education should build critical theoretical knowledge about entrepreneurship and equip students with the management skills imperative for an entrepreneurial career. Therefore, academics should teach students theory to supplement practical learning experience. In practice raising awareness of entrepreneurship can thus be achieved through teaching examples and by inviting entrepreneurs as guest lecturers. It can further be concluded that entrepreneurship is critical and practical aspects is imperative to enhance the intentionality of creating ventures.

\section{RECOMMENDATIONS}

Based on these findings, it is strongly recommended that: (1) a more refined and developed face of entrepreneurship be provided at the two universities; (2) entrepreneurship be introduced as a discipline that leads to an academic qualification; (3) teaching/learning methods give more attention to a practical approach to entrepreneurship; for example, students could b required to prepare a business plan, which would be assessed by people from a financial institution and receive some rewards (capital to start the business); (4) the quality of methodological approach on entrepreneurship education be improved; (5) fewer traditional assessment methods be adopted at the two universities in Botswana and (6) lecturers be encouraged to introduce entrepreneurial and self-employed perspectives in their teaching based on their own experience and knowledge of entrepreneurship.

\section{FUTURE RESEARCH DIRECTION}

Future research could investigate the views of academic staff members, particularly those teaching entrepreneurship educations. Graduates who went through the programmes could be surveyed to obtain their views on entrepreneurship education and career options after they have completed the courses.

\section{REFERENCES}

Alberti FG, Sciascia S, Poli A (2004). Entrepreneurship Education: Notes on an ongoing debate. Proceedings of the $14^{\text {th }}$ Annual IntEnt Conference. University of Napoli Federico II, Italy. 4-7 July.
Alberti FG, Sciascia S, Poli A (2005). The domain of entrepreneurship education: key issues. Intern. J. Entrep. Educ. 2(4):453-482.

Carey C, Naudin A (2006). Enterprise curriculum for creative industries students: an exploration of current attitudes and issues. Educ. Train. 48(7):518-531.

Cheng MY, Chan WS, Mahmood A (2009). The effectiveness of entrepreneurship education in Malaysia. Educ. Train. 48(7):555-566.

European Commission (2008). Entrepreneurship education in higher education, especially within non-business studies. Final report of the expect group. Enterprise and Industry Directorate-General. Brussels, Belgium.

Fayolle A, Gailly B, Lassarc-Clerc N (2006). Assessing the impact of entrepreneurship education programmes: a new methodology. J. Eur. Indust. Train. 30(9):701-720.

Fayolle A, Gailly B (2008). From craft to science. Teaching models and learning processes in entrepreneurship education. J. Eur. Indust. Train. 32 (7):569-593.

Galloway L, Brown W (2002). Entrepreneurship education at university: a driver in the creation of high growth firms? Educ. Train. 44(8/9):398-405.

Garavan TN, O'cinneide B (1994). Entrepreneurship education and training programmes: a review and evaluation - part 1. J. Eur. Indust. Train. 18(8):3-12.

GEM (2006). Global Entrepreneurship Monitor Report. Babson College, Kauffman Centre for Entrepreneurship, Babson, MA and London School of Economics, London.

Gurol Y, Atsan N (2006). Entrepreneurial characteristics amongst university students: some insights for entrepreneurship education and training in Turkey. Educ. Train. 48(1):25-38.

Hamidi DY, Wennberg K, Berglund H (2008). Creativity in entrepreneurship education. J. Small Bus. Enterp. Dev. 15(2):304320.

Henry C Hill F, Leitch C (2005). Entrepreneurship education and training: can entrepreneurship be taught? Part 1. Educ. Train. 47(2):98-111

Jack SL, Anderson AR (1999). Entrepreneurship education within the enterprise culture: producing reflective practitioners. Int. J. Entrep. Behav. Res. 5(3):110-125.

Jack SL, Anderson AR (2008). Typologies for enterprising education: the professional artisan? J. Small Bus. Enterp. Dev. 15(2):259-273.

Jesselyn COM, Mitchell B (2006). Entrepreneurship education in South Africa: a nationwide survey. Educ. Train. 48(5):348-359.

Katz JA (2003). The chronology and intellectual trajectory of American entrepreneurship education. J. Bus. Vent. 18(2):283-300.

Kirby DA (2004). Entrepreneurship education: can business schools meet the challenge? Educ. Train. 46(8/9):510-519.

Kolb DA (1984). Experiential Learning. Experiences as the source of learning and development. Englewood, NJ: Prentice Hall.

Kuratko DF (2003). Entrepreneurship education: emerging trends and challenges for the 21st century. Coleman Foundation White Papers Series for the US. Paper presented at the Association of Small Business and Entrepreneurship. Retrieved from: http://www.usasbe.org/pdf/CWP-2003-Kuratko.pdf. Accessed: $16 / 04 / 2009$.

Matlay H (2006). Researching entrepreneurship and education, part 2: what is entrepreneurship and does it matter? Educ. Train. 48(8/9):704-718.

Matlay H, Carey C (2007). Entrepreneurship education in the UK: a longitudinal perspective. J. Small Bus. Enterp. Dev. 14 (2):252-263.

Mwasalwiba ES (2010). Entrepreneurship education: a review of its objectives, teaching methods, and impact indicators. Educ. Train. 52(1):20-47.

Nabi G, Holden R (2008). Graduate entrepreneurship: intentions, education and training. Educ. Train. 50(7):545-551.

Nieman G, Nieuwenhuizen C (2008). Entrepreneurship: A South African perspective. $2^{\text {nd }}$ ed. Pretoria: Van Schaik Publishers.

Niyonkuru R (2005). Entrepreneurship education at tertiary institutions in Rwanda: A situational analysis. Western Cape, University of Western Cape.

Petridou E, Sarri A, Kyrgidou LP (2009). Entrepreneurship education in higher educational institutions: the gender dimension. Gender in Management: Int. J. 24(4):286-309. 
Pittaway L, Hannon P, Gibb A, Thompson J (2009). Assessment practice in entrepreneurship education. Int. J. Entrep. Behav. Res. 15(1):71-93.

Rasmussen EA, Sorheim R (2006). Action-based entrepreneurship education. Technovation, 26: 185-194.

Solomon $\mathrm{G}$ (2007). An examination of entrepreneurship education in the United States. J. Small Bus. Enterp. Dev. 14(2):168-182.

Tucker D, Selcuk SS (2009). Which factors affect entrepreneurial intention of university students? J. Eur. Indust. Train. 33(2):142-159.
Volkmann C, Wilson KE, Mariotti S, Rabuzzi D, Vyakarnam S, Sepulveda A (2009). Educating the next wave of entrepreneurs: unlocking entrepreneurial capabilities to meet the global challenges of the $21^{\text {st }}$ century - a report of the Global Foundation Initiative, World Economic Forum, pp. 1-184. 